\title{
Assessment of Clarias gariepinus as a biological control agent against mosquito larvae
}

\author{
Buze Chala ${ }^{1}$, Berhanu Erko ${ }^{2 *}$, Abebe Animut ${ }^{2}$, Abraham Degarege ${ }^{2,3}$ and Beyene Petros ${ }^{4}$
}

\begin{abstract}
Background: The emergence and spread of insecticide resistant mosquitoes renewed interest in investigating the use of larvivorous fish as a biological control agent. The potential of Clarias gariepinus fish in controlling Anopheles arabiensis and culicine larvae was assessed under laboratory and semi-field conditions.

Results: Small size $(15-20 \mathrm{~cm})$ C. gariepinus fish consumed greater number of mosquito larvae than the large size fish $(25-40 \mathrm{~cm})$ in the multivariate regression model $(\beta=13.36,95 \% \mathrm{Cl}=4.57,22.15)$. The Anopheles larvae consumed was greater in number than the culicines larvae consumed by the fish $(\beta=12.10,95 \% \mathrm{Cl}=3.31,20.89)$. The number of larvae consumed was greater during the night hours than during the light hours $(\beta=30.06,95 \% \mathrm{Cl}=21.27$, 38.85). Amount of supplementary fish food did not cause significant differences in the number of mosquito larvae consumed by the fish among different groups. C. gariepinus was observed to feed on mosquito larvae under laboratory and semi-field conditions.
\end{abstract}

Conclusion: C. gariepinus fed on the larvae of An. arabiensis and culicines readily. Hence, it can be used as an alternative mosquito control agent in Ethiopia where the breeding habitats are small and localized.

Keywords: Clarias gariepinus, Biological control, Larvae, Anopheles arabiensis, Culex, Ethiopia

\section{Background}

Current malaria vector control strategies depend mainly on long-lasting insecticidal nets (LLINs) and indoor residual spraying (IRS). These interventions contributed to the reduction of malaria-related cases and deaths globally. However, the gains are threatened due to the emergence and spread of vectors that are physiologically and behaviourally resistant to the insecticides [1-3].

Besides the development of insecticide resistance in malaria vectors, increased concern of environmental pollution with insecticides have aroused interest in developing environment-friendly approaches such as the use of biological control agents $[4,5]$ including larvivorous fishes.

\footnotetext{
*Correspondence: berhanue@yahoo.com; berhanu.erko@aau.edu.et

2 Aklilu Lemma Institute of Pathobiology, Addis Ababa University,

P. O. Box 1176, Addis Ababa, Ethiopia

Full list of author information is available at the end of the article
}

Over the past 100 years, several fish species have been documented to feed on mosquito larvae in different parts of the world among which many are proved effective $[6,7]$. One of these species is Clarias gariepinus [7-9]. It is an opportunistic feeder targeting insects, worms, mollusks, gastropods, crustaceans, small fishes, aquatic plants and debris that can fit into its mouth [8]. In an effort to control mosquito-borne diseases, targeting the immature stages of mosquitoes (eggs, larvae and pupae) can be more effective as these stages are confined within relatively small aquatic habitats, relatively immobile and cannot readily escape the fish. In Ethiopia, C. gariepinus occurs almost in all water bodies that can support fish [10]. However, the efficacy of this fish in devouring mosquito larvae is poorly understood. In the present study, we assessed the efficacy of $C$. gariepinu as a biological control agent against mosquito (Anopheles and Culex) larvae in laboratory and semi-field conditions. 


\section{Methods}

\section{Clarias gariepinus fish}

A colony of C. gariepinus fish and its supplementary food was obtained from the Sebeta National and Other Living Aquatic Resources Research Center (NFLARRC) of Ethiopia, near Sebeta Town, located at $20 \mathrm{~km}$ on the road to Jimma Town. The fish was maintained in glass aquaria $(60 \times 40 \times 35 \mathrm{~cm})$ and acclimatized at room temperature $\left(25 \pm 2{ }^{\circ} \mathrm{C}\right)$ before the experiment began. Aquaria air pumps were used to aerate the water in the aquaria.

\section{Anopheles and Culex larvae}

Anopheles arabiensis larvae used in the experiment was obtained from the Aklilu Lemma Institute of Pathobiology (ALIPB) insectary whereas culicine larvae were obtained from the ponds of the ALIPB.

\section{Laboratory based mosquito predation experiment}

Nine clean glass aquaria (each $40 \times 20 \times 26 \mathrm{~cm}$ ), each filled with $15 \mathrm{~L}$ of aged tap water, were arranged in three groups. A total of 50, 100 or $150 \mathrm{An}$. arabiensis/culicine larvae were introduced into the 1st, 2nd and 3rd in triplicates. The first group was supplied with adequate supplementary fish food, the second with inadequate food and the third with no food. Inadequate food is supplementary food given for each C. gariepinus, which was about $2 \%$ of each fish body weight while adequate food was about $4 \%$ of each fish body weight as previously used [11]. Either small $(15-20 \mathrm{~cm})$ or large $(25-40 \mathrm{~cm})$ fish was placed into the first, second and third (control) groups. The experiment was conducted in the day light $(12 \mathrm{~h})$ and night dark hours $(12 \mathrm{~h})$ to compare larval predation by the catfish. The experiment for the day light hour started in the morning (6:00 am) and larval predation by the fish was recorded in the early evening (6:00 pm). The experiment for the day night hour was started in the early evening $(6: 00 \mathrm{pm})$ and larval predation by the fish was recorded in the early morning (6:00 am).

\section{Semi-field based Anopheles arabiensis larvae predation experiment}

Semi-field larval predation experiment was carried out in four ponds of equal size $(1.05 \mathrm{~m} \times 0.40 \mathrm{~m} \times 1 \mathrm{~cm})$ built on the premises of the ALIPB. The ponds were washed and covered with mosquito proof net before and after introducing catfish and mosquito larvae. This was done to prevent escape of emerging adult mosquitoes and incoming egg laying mosquitoes. About $0.21 \mathrm{~m}^{3}$ of water and 300 Anopheles arabiensis larvae were introduced into each of the four clean ponds. The ponds were then categorized as group 1, 2, 3 and 4. Following the grouping, a small size fish $(15-20 \mathrm{~cm})$, a medium size fish $(20-25 \mathrm{~cm})$ and a large size fish $(25-40 \mathrm{~cm})$ were introduced into the $1 \mathrm{st}$, 2nd and 3rd group, respectively. No fish was introduced into the 4th group (control). Supplementary fish food was added in each of the experimental groups, but not in the control.

\section{Data analysis}

Data were double entered in excel-sheet and analyzed using STATA version 11 (STATA Corporation, College Station, Texas, USA). Percentage of mosquito larvae consumed was calculated by dividing the number of mosquito larvae consumed by the number of mosquito larvae exposed. $Z$ test was used to compare the percentage of mosquito (anopheline or culicines) larvae consumed by small and large sized fish during night and light hours. Multivariable regression analysis was used to quantify the impact of fish size, exposure hour (day light hour and night hour), mosquito genus (Anopheles or Culex), number of mosquito larvae exposed and amount of supplementary food added on the feeding efficacy of the fish. $95 \%$ CI values were calculated for the average mean difference of mosquito larvae consumed between different groups. Values were considered significant when $\mathrm{p}<0.05$ or when $95 \%$ CI values did not include zero.

\section{Results}

Feeding activity of Clarias gariepinus on Anopheles arabiensis larvae in the laboratory

Clarias gariepinus was found to feed on most mosquito larvae it encountered both in the laboratory and in the semi-field conditions. Small size $C$. gariepinus consumed most of the An. arabiensis larvae it encountered and the night hour consumption (96.9\%) was significantly $(\mathrm{p}<0.01)$ higher than the light hours $(83.8 \%)$ (Table 1). Likewise, large size C. gariepinus consumed all larvae (100\%) during night hours, which was a significantly $(\mathrm{p}<0.01)$ higher rate compared to the light hours (78.6\%). There was no significant difference in the larval consumption by large size $C$. gariepinus, among the groups having 50, 100 and 150 larvae. The percentage of larval consumption was similar among the groups with the different amount of supplementary fish food.

Small size $C$. gariepinus consumed larger number of An. arabiensis than the large size C. gariepinus. During the light hours, larval consumption by small size fish $(83.7 \%)$ was greater than the consumption by the large size fish $(78.6 \%)$. During the night hours, percentage of larvae consumed by large size C. gariepinus (100\%) was slightly greater than the percentage consumed by small size C. gariepinus (96.9\%).

\section{Feeding activity of Clarias gariepinus on culicine larvae under the laboratory condition}

Culicine larvae consumption by small size (100\%) and large size $(97.4 \%)$ C. gariepinus during night hours was 
Table 1 Predation of Clarias gariepinus on Anopheles arabiensis larvae during day light and day night hours

\begin{tabular}{|c|c|c|c|c|c|c|c|}
\hline \multirow[t]{2}{*}{ Fish size } & \multirow{2}{*}{$\begin{array}{l}\text { Number } \\
\text { exposed }\end{array}$} & \multirow[t]{2}{*}{ Fish food } & \multicolumn{2}{|c|}{ Light hour (From 6:00 am to 6:00 pm) } & \multicolumn{2}{|c|}{ Night hour (from 6:00 pm to $6: 00 \mathrm{am}$ ) } & \multirow[t]{2}{*}{$\mathrm{p}$ values } \\
\hline & & & $\begin{array}{l}\text { Average } \\
\text { consumed (SE) }\end{array}$ & $\begin{array}{l}\text { Percent } \\
\text { consumed }\end{array}$ & $\begin{array}{l}\text { Average } \\
\text { consumed (SE) }\end{array}$ & $\begin{array}{l}\text { Percent } \\
\text { consumed }\end{array}$ & \\
\hline \multirow[t]{9}{*}{ Small } & 50 & Adequate & $41.7(6.1)$ & 83.3 & $46.7(3.3)$ & 93.3 & 0.119 \\
\hline & 50 & Inadequate & $41.7(4.4)$ & 83.3 & $50.0(0.0)$ & 100.0 & 0.001 \\
\hline & 50 & No food & $40.7(2.3)$ & 81.3 & $43.3(6.7)$ & 86.7 & 0.461 \\
\hline & 100 & Adequate & $76.3(11.6)$ & 76.3 & $100.0(0.0)$ & 100.0 & $<0.001$ \\
\hline & 100 & Inadequate & $76.7(8.8)$ & 76.7 & $93.3(6.7)$ & 93.3 & 0.018 \\
\hline & 100 & No food & $78.3(6.0)$ & 78.3 & $100.0(0.0)$ & 100.0 & 0.001 \\
\hline & 150 & Adequate & $146.0(1.2)$ & 97.3 & $148.3(1.7)$ & 98.9 & 0.558 \\
\hline & 150 & Inadequate & $135.3(2.9)$ & 90.2 & $150.0(0.0)$ & 100.0 & 0.023 \\
\hline & 150 & No food & $130.0(10.4)$ & 86.7 & $150.0(0.0)$ & 100.0 & 0.008 \\
\hline \multirow[t]{9}{*}{ Large } & 50 & Adequate & $45.0(2.9)$ & 90.0 & $50.0(0.0)$ & 100.0 & 0.022 \\
\hline & 50 & Inadequate & $40.0(2.9)$ & 80.0 & $50.0(0.0)$ & 100.0 & $<0.001$ \\
\hline & 50 & No food & $41.0(2.1)$ & 82.0 & $50.0(0.0)$ & 100.0 & 0.002 \\
\hline & 100 & Adequate & $79.0(0.6)$ & 79.0 & $100.0(0.0)$ & 100.0 & 0.001 \\
\hline & 100 & Inadequate & 76.7 (1.7) & 76.7 & $100.0(0.0)$ & 100.0 & $<0.001$ \\
\hline & 100 & No food & 76.7 (7.3) & 76.7 & $100.0(0.0)$ & 100.0 & $<0.001$ \\
\hline & 150 & Adequate & $105.0(2.9)$ & 70.0 & $150.0(0.0)$ & 100.0 & $<0.001$ \\
\hline & 150 & Inadequate & $110.0(2.9)$ & 73.3 & $150.0(0.0)$ & 100.0 & $<0.001$ \\
\hline & 150 & No food & $120.0(5.8)$ & 80.0 & $150.0(0.0)$ & 100.0 & 0.001 \\
\hline
\end{tabular}

Note: Average larvae consumed is the mean of the number of larvae consumed for three replicate experiments

$P$ values significance test on the comparison of percent of Anopheles arabiensis larvae consumed between day light and day night hours

significantly $(\mathrm{p}<0.01)$ greater compared to the corresponding consumption of 77.7 and $39.6 \%$ during light hours (Table 2). Consumption of large size C. gariepinus decreased significantly $(\mathrm{p}<0.01)$ with the increase in the number of culicine larvae per group during the day light hours.

Percentage of culicine larvae consumed by small size $C$. gariepinus, during light hour, was significantly $(\mathrm{p}<0.01)$ greater in the groups with no fish food $(81.1 \%)$ or inadequate fish food $(82.8 \%)$ compared to the groups with adequate food $(69.1 \%)$. However, the percentage of culicine larvae consumed by large size $C$. gariepinus during light hour was significantly $(\mathrm{p}<0.01)$ greater in the groups with adequate $(50 \%)$ or inadequate $(41.1 \%)$ food compared to the groups with no food $(27.8 \%)$. On the other hand, the percentage of culicine larvae consumed by small and large $C$. gariepinus during night hours was similar among experiments with adequate, inadequate or no food at all and among experiments with different number of mosquito exposed (50, 100 and 150).

The percentage of culicine larvae consumed by small $C$. gariepinus during light $(73.9 \%)$ and night $(100 \%)$ hours was significantly greater than the percentages consumed by large size $C$. gariepinus during light (39.6\%) and night $(97.4 \%)$ hours, respectively $(\mathrm{p}<0.01)$.
Large size C. gariepinus consumed greater number of Anopheles than culicine larvae during light (\% consumed $=78.6$ vs. $39.6, \mathrm{z}=9.72, \mathrm{p}<0.01)$ and night $(\%$ consumed $=100$ vs. 97.4, $\mathrm{p}<0.01$ ) hours. Small size $C$. gariepinus consumed greater number of culicine than anopheline larvae during night hours (\% consumed $=100$ vs. 96.9, $\mathrm{p}<0.01)$. The difference between the number of culicine and anopheline larvae consumed by small size $C$. gariepinus was not significant during light hours.

Small size C. gariepinus fish consumed greater number of mosquito larvae than the large size in the multivariable regression model $(\beta=13.36,95 \% \mathrm{CI}=4.57,22.15)$ (Table 3). The number of Anopheles larvae consumed was greater than the number of culicine larvae consumed by the fish $(\beta=12.10,95 \% \mathrm{CI}=3.31,20.89)$. In the model, the number of larvae consumed was greater during the night hours than during the light hours $(\beta=30.06,95 \%$ $\mathrm{CI}=21.27,38.85$ ). The number of mosquito larvae consumed also increased significantly with the increase in the number of mosquito exposed. However, differences in the number of mosquito consumed were not significant among experiments where food was added at adequate or inadequate level or not at all. More than $80 \%$ of Anopheles and Culex larvae placed in aquaria without C. gariepinus developed into adult mosquitoes within 2 weeks (Table 4). 
Table 2 Predation of Clarias gariepinus on Culex mosquitoes during light and night hours

\begin{tabular}{|c|c|c|c|c|c|c|c|}
\hline \multirow[t]{2}{*}{ Fish size } & \multirow{2}{*}{$\begin{array}{l}\text { Number } \\
\text { exposed }\end{array}$} & \multirow[t]{2}{*}{ Fish food } & \multicolumn{2}{|c|}{ Light hour (From 6:00 am to 6:00 pm) } & \multicolumn{2}{|c|}{ Night hour (from 6:00 pm to 6:00 am) } & \multirow[t]{2}{*}{ p value } \\
\hline & & & $\begin{array}{l}\text { Average } \\
\text { consumed (SE) }\end{array}$ & $\begin{array}{l}\text { Percent } \\
\text { consumed }\end{array}$ & $\begin{array}{l}\text { Average } \\
\text { consumed (SE) }\end{array}$ & $\begin{array}{l}\text { Percent } \\
\text { consumed }\end{array}$ & \\
\hline \multirow[t]{9}{*}{ Small } & 50 & Adequate & $25.0(2.9)$ & 50.0 & $50.0(0.0)$ & 100.0 & $<0.001$ \\
\hline & 50 & Inadequate & $40.0(2.9)$ & 80.0 & $50.0(0.0)$ & 100.0 & 0.001 \\
\hline & 50 & No & $45.0(2.9)$ & 90.0 & $50.0(0.0)$ & 100.0 & 0.023 \\
\hline & 100 & Adequate & $60.0(8.7)$ & 60.0 & $100.0(0.0)$ & 100.0 & $<0.001$ \\
\hline & 100 & Inadequate & $85.0(2.9)$ & 85.0 & $100.0(0.0)$ & 100.0 & 0.004 \\
\hline & 100 & No & $80.0(2.0)$ & 80.0 & $100.0(0.0)$ & 100.0 & 0.001 \\
\hline & 150 & Adequate & $146.0(1.2)$ & 97.3 & $150.0(0.0)$ & 100.0 & 0.217 \\
\hline & 150 & Inadequate & $125.0(2.9)$ & 83.3 & $150.0(0.0)$ & 100.0 & 0.002 \\
\hline & 150 & No & $110.0(5.8)$ & 73.3 & $150.0(0.0)$ & 100.0 & $<0.001$ \\
\hline \multirow[t]{9}{*}{ Large } & 50 & Adequate & $41.7(4.4)$ & 83.3 & $50.0(0.0)$ & 100.0 & 0.002 \\
\hline & 50 & Inadequate & $25.0(2.9)$ & 50.0 & $43.3(2.0)$ & 86.7 & $<0.001$ \\
\hline & 50 & No & $23.3(1.7)$ & 46.7 & $50.0(0.0)$ & 100.0 & $<0.001$ \\
\hline & 100 & Adequate & $40.0(2.9)$ & 40.0 & $100.0(0.0)$ & 100.0 & $<0.001$ \\
\hline & 100 & Inadequate & $40.0(2.9)$ & 40.0 & $90.0(2.9)$ & 90.0 & $<0.001$ \\
\hline & 100 & No & $16.7(4.4)$ & 16.7 & $100.0(0.0)$ & 100.0 & $<0.001$ \\
\hline & 150 & Adequate & $40.0(5.8)$ & 26.7 & $150.0(0.0)$ & 100.0 & $<0.001$ \\
\hline & 150 & Inadequate & $50.0(5.8)$ & 33.3 & $150.0(0.0)$ & 100.0 & $<0.001$ \\
\hline & 150 & No & $30.0(5.8)$ & 20.0 & $150.0(0.0)$ & 100.0 & $<0.001$ \\
\hline
\end{tabular}

Note: Average larvae consumed is the mean of the number of larvae consumed for three replicate experiments

$P$ values significance test on the comparison of percent of Culex larvae consumed between day light and day night hours

\section{Feeding activity of Clarias gariepinus on An. arabiensis under semi-field condition}

Out of $300 \mathrm{An}$. arabiensis larvae placed in ponds where no catfish was introduced, 200 (67\%) emerged into adults within 7-14 days (Table 5). On the other hand, in the other 3 experimental groups, where small, medium or large size catfish and 300 Anopheles larvae were added, no adult mosquito emerged.

\section{Discussion}

African catfish, Clarias gariepinus, was observed to feed on the larvae of Anopheles arabiensis and culicine mosquitoes under laboratory and semi-field conditions. The fish consumed the larvae in the presence or absence of supplementary fish food and also with different larval density. Larval consumption was significantly correlated with the size of the fish, mosquito genera, number of mosquito initially exposed and period of exposure (day light or day night hours).

C. gariepinus consumed greater number of larvae during the night (from 6:00 pm to 6:00 am) than during the light hours. The larval feeding activity of $C$. gariepinus was reported to be higher in dark hours than in the light hours, or alternating light and dark conditions [12, 13]. The feeding activity of the fish was found to be affected by its sensory organs rather than its visual sense organs
$[14,15]$. The test buds and free neurocytes are common in the fish; hence the fish gets active to feed in dark conditions. In addition, the activities of mosquito larvae increase at night hours $[15,16]$, making them easily exposed to the fish.

Percentage of larval consumption was greater in experiments that involved small size $C$. gariepinus than those with the large size. Small size fish are at a lower risk of recognition by predators and usually remain active in day and night hours. These attributes make them better and potent control agents for mosquito larvae. Larvivorous fish which are small, hardy and capable of getting about easily in shallow waters among thick weeds are usually preferred to control mosquito larvae. Crustaceans, insect larvae, small vertebrates, invertebrates and young fishes make up the diet of small C. gariepinus [17]. Furthermore, young fish may also have higher metabolic rates compared to large adult fish, necessitating more intake of larvae and other food. On the other hand, large size $C$. gariepinus prefers to feed more on larger prey compared with small ones $[18,19]$.

C. gariepinus consumed greater number of $A n$. arabiensis larvae than culicine. This could be due to the lower motility rate and water surface resting behavior of $A n$. arabiensis larvae, which exposes them for easy detection by the fish. On the other hand, culicine mosquito 
Table 3 Effect of fish size, mosquito species, number of larvae exposed, supplementary food and hour of larval exposure on the predation of Clarias gariepinus on mosquito larvae

\begin{tabular}{|c|c|c|c|}
\hline Variable & $\begin{array}{l}\text { Average No. of } \\
\text { larvae consumed }\end{array}$ & $\begin{array}{l}\text { Crude mean difference in the Average } \\
\text { No. of larvae consumed during light or } \\
\text { night hours }(95 \% \mathrm{Cl})\end{array}$ & $\begin{array}{l}\text { Adjusted mean difference in the } \\
\text { Average Number of mosquito larvae } \\
\text { during light or night hours }(95 \% \mathrm{Cl})\end{array}$ \\
\hline \multicolumn{4}{|l|}{ Fish size } \\
\hline Large & 77.31 & - & - \\
\hline Small & 90.67 & $13.36(-6.57,33.29)$ & $13.36(4.57,22.15)$ \\
\hline \multicolumn{4}{|l|}{ Mosquito } \\
\hline Culex & 77.94 & - & - \\
\hline Anopheles & 90.04 & $12.10(-7.87,32.07)$ & $12.10(3.31,20.89)$ \\
\hline \multicolumn{4}{|l|}{ No. of larvae } \\
\hline 50 & 43.05 & - & - \\
\hline 100 & 82.03 & $38.97(24.35,53.59)$ & $38.97(28.21,49.74)$ \\
\hline 150 & 126.90 & $83.85(69.22,98.47)$ & $83.85(73.08,94.61)$ \\
\hline \multicolumn{4}{|l|}{ Fish food } \\
\hline No food & 82.71 & - & - \\
\hline Inadequate & 84.25 & $1.54(-23.35,26.43)$ & $1.54(-9.22,12.30)$ \\
\hline Adequate & 85.03 & $2.32(-22.57,27.21)$ & $2.31(-8.45,13.08)$ \\
\hline \multicolumn{4}{|l|}{ Hours of exposure } \\
\hline Light (6:00 am-6:00 pm) & 68.96 & - & - \\
\hline Night (6:00 pm-6:00 am) & 99.03 & $30.06(11.20,48.93)$ & $30.06(21.27,38.85)$ \\
\hline
\end{tabular}

Note: Average larvae consumed is the mean of the number of larvae consumed for three replicate experiments

Table 4 Emergence of adult Anopheles and Culex mosquito within two weeks after introduction of the larvae in aquaria without Clarias gariepinus

\begin{tabular}{lccl}
\hline Larval type & $\begin{array}{l}\text { Larval } \\
\text { density }\end{array}$ & $\begin{array}{l}\text { Number of } \\
\text { adults emerged }\end{array}$ & $\begin{array}{l}\text { \% of adult } \\
\text { mosquitoes } \\
\text { emerged }\end{array}$ \\
\hline Culicine larvae & 50 & 42 & 84 \\
& 100 & 92 & 92 \\
Anopheles larvae & 150 & 147 & 98 \\
& 50 & 48 & 96 \\
& 100 & 89 & 89 \\
& 150 & 130 & 87 \\
\hline
\end{tabular}

Table 5 Feeding activity of Clarias gariepinus against Anopheles arabiensis larvae ( $n=300$ per group) in semifield experiment, May 2013

\begin{tabular}{llllll}
\hline $\begin{array}{l}\text { Treat- } \\
\text { ment } \\
\text { groups }\end{array}$ & $\begin{array}{l}\text { Supple- } \\
\text { mentary } \\
\text { food }\end{array}$ & $\begin{array}{l}\text { Larvae } \\
\text { con- } \\
\text { sumed }\end{array}$ & $\begin{array}{l}\% \\
\text { of dead } \\
\text { larvae or } \\
\text { adults }\end{array}$ & $\begin{array}{l}\% \\
\text { of adults } \\
\text { mosquito } \\
\text { emerged }\end{array}$ & $\begin{array}{l}\text { Time } \\
\text { taken }\end{array}$ \\
\hline Large fish & $\begin{array}{c}\text { Inad- } \\
\text { equate }\end{array}$ & All & - & - & 3 days \\
$\begin{array}{c}\text { Medium } \\
\text { Inad- } \\
\text { fish }\end{array}$ & All & - & - & 3 days \\
$\begin{array}{c}\text { Small fish } \\
\text { Inad- } \\
\text { equate }\end{array}$ & All & - & - & 3 days \\
No fish & - & - & 33 & 67 & $7-14$ days \\
\hline
\end{tabular}

larvae make frequent mobility in water bodies thereby avoiding easy capture by the fish. C. gariepinus detects food with its sensory barbells before securing with its teeth and gulping, thus $C$. gariepinus prefer inactive preys $[17,20]$.

There was significant correlation between the number of mosquito larvae consumed and the number of mosquito larvae initially exposed. Larval consumption was higher in groups with large number of mosquitoes (e.g. $\mathrm{n}=150)$ than in groups with small numbers $(\mathrm{n}=100$ or $\mathrm{n}=50$ ). However, the number of mosquito larvae consumed was similar among the groups with the different amount of supplementary fish food.

In some of the laboratory control experiments where mosquito of different larval density were introduced into an aquaria without $C$. gariepinus, $90 \%$ of the mosquito larvae added developed into adults. Similarly, in pond experiments, about $66 \%$ of mosquito larvae placed in aquaria without $C$. gariepinus developed into adults. On the other hand, all the mosquito larvae in the experimental groups in which C. gariepinus introduced were consumed by the fish. This finding was in agreement with the previous experimental evidence for mosquito larva consumption by the catfish [21].

C. gariepinus can endure extremely harsh conditions and able to tolerate very low oxygen rmis concentrations allowing ease of local production and transportation of the fish 
$[14,20]$. In addition, the habitat of $C$. gariepinus overlaps with those of mosquito larvae [11]. The observation that $C$. gariepinus feeds on Biomphalaria pfeifferi (the intermediate host of Schistosoma mansoni) [11] also makes this fish a good candidate for biological control agent against the mosquitoes and snail intermediate hosts as their habitats overlap in many cases. Nevertheless, introduction of alien fish species into a natural ecosystem as a biocontrol agent could threaten native fish species and other aquatic biota through introduction of disease causing pathogens, predatory and biological competition [22].

\section{Conclusions}

The greater percentage of Anopheles and culicine larvae were consumed when introduced to aquaria containing C. gariepinus during day and night hours. The feeding efficacy of $C$. gariepinus showed significant correlation with the size of the fish, hours of feeding, mosquito species and number exposed. However, further studies about the feeding efficacy of the fish in pools and ponds and long term environmental effects of C. gariepinus on other aquatic species should be carefully examined before recommending its introduction for biological control of mosquitoes.

\section{Abbreviations}

IRS: indoor residual spraying; LLITNs: long-lasting insecticide treated nets; NFLARRC: National Fisheries and Other Living Aquatic Resources Research Centre; ALIPB: Aklilu Lemma Institute of Pathobiology; Cl: confidence interval.

\section{Authors' contributions}

$\mathrm{BE}$ and $\mathrm{AA}$ conceived the idea, $\mathrm{BC}, \mathrm{BE}, \mathrm{AA}, \mathrm{AD}$ and $\mathrm{BP}$ designed and approved the experiment, $B C$ prepared the first draft, $B C, A A$ and $A D$ analyzed the data. All authors read and approved the final manuscript.

\section{Author details}

${ }^{1}$ Arba Minch University, P. O. Box 21, Arba Minch, Ethiopia. ${ }^{2}$ Aklilu Lemma Institute of Pathobiology, Addis Ababa University, P. O. Box 1176, Addis Ababa, Ethiopia. ${ }^{3}$ Department of Epidemiology, Robert Stempel College of Public Health and Social Work, Florida International University, Miami, FL, USA. ${ }^{4}$ Microbial, Cellular and Molecular Biology Department, College of Natural Sciences, Addis Ababa University, P. O. Box 1176, Addis Ababa, Ethiopia.

\section{Acknowledgements}

We would like to acknowledge Microbial, Cellular and Molecular Biology Department, College of Natural Sciences, Addis Ababa University, for the financial support of this work. We would also like to duly acknowledge the Aklilu Lemma Institute of Pathobiology for permission to use its laboratory and pond as well as for provision of all the necessary materials needed for the experiment. The fishes used for the experiment and fish food were provided free of charge by NFLARRC in natural ponds of Sebeta.

\section{Availability of data and materials}

Nearly all data are available in the paper itself.

\section{Competing interests}

The authors declare that they have no competing interests.

\section{Ethics}

The study obtained ethical clearance before its implementation from the Institutional Ethics Review Board of College of Natural Sciences,
Addis Ababa University. The fishes used in the experiment were given the humane treatment of animals used in research investigation.

\section{Funding}

The work was an MSc research of the first author and it was funded by the Microbial, Cellular and Molecular Biology Department, College of Natural Sciences of the Addis Ababa University.

Received: 16 August 2015 Accepted: 17 May 2016

Published online: 31 May 2016

References

1. Balkew M, Ibrahim M, Koekemoer LL, Brooke BD, Engers H, Aseffa A Gebre-Michael T, Elhassen I. Insecticide resistance in Anopheles arabiensis (Diptera: Culicidae) from villages in central, northern and south west Ethiopia and detection of kdr mutation. Parasit Vectors. 2010;3:40.

2. Edi CV, Koudou BG, Jones CM, Weetman D, Ranson H. Multiple-insecticide resistance in Anopheles gambiae mosquitoes, Southern Cote d'Ivoire. Emerg Infect Dis. 2012;18:1508-11.

3. Protopopoff N, Matowo J, Malima R, Kavishe R, Kaaya R, Wright A, West PA Kleinschmidt I, Kisinza W, Mosha FW, Rowland M. High level of resistance in the mosquito Anopheles gambiae to pyrethroid insecticides and reduced susceptibility to bendiocarb in north-western Tanzania. Mal J. 2013;12:149.

4. WHO. Use of Fish for Mosquito Control. World Health Organization, Regional Office for the Eastern Mediterranian Region, Cairo 2003.

5. WHO. Larval Source Managment: A supplementary Measure for Malaria Vector Control, An Operational Manual. www.who.int/malaria/publications/atoz/9789241505604/en/. 2013.

6. Howard AF, Zhou G, Omlin FX. Malaria mosquito control using edible fish in western Kenya: preliminary findings of a controlled study. BMC Public Health. 2007;7:199.

7. Rozendaal J.Vector control: methods for use by individuals and communities. Geneva: World Health Organization; 1997.

8. Ghosh SK, Tiwari SN, Sathyanarayan TS, Sampath TR, Sharma VP, Nanda N, Joshi H, AdakT, Subbarao SK. Larvivorous fish in wells target the malaria vector sibling species of the Anopheles culicifacies complex in villages in Karnataka, India. Trans R Soc Trop Med Hyg. 2008;2005(99):101-5.

9. WHO. Manual on environmental management for mosquito control: with special emphasis on malaria vectors. Geneva: World Health Organization; 1982.

10. Killeen GF, Fillinger U, Knols BG. Advantages of larval control for African malaria vectors: low mobility and behavioural responsiveness of immature mosquito stages allow high effective coverage. Mal J. 2002;1:8.

11. Gashaw F, Erko B, Teklehaymanot T, Habtesellasie R. Assessment of the potential of competitor snails and African catfish (Clarias gariepinus) as biocontrol agents against snail hosts. Trans R Soc Trop Med Hyg. 2008;102(8):774-9.

12. Almazan-Rueda PSJ, Verreth AJ. Behavioral responses under feeding methods and light regimes of the African catfish (Clarias gariepinus) juveniles. Aquaculture. 2004:231:347-59.

13. Adewolu MA, Adeniji CA, Adejobi AB. Feed utilization, growth and survival of Clarias gariepinus (Burchell 1822) fingerlings cultured under different photoperiods. Aquaculture. 2008;283:64-7.

14. Hecht T, Appelbaum S. Observations on intraspecific aggression and coeval sibling cannibalism by larval and juvenile Clarias gariepinus (Clariidae: Pisces) under controlled conditions. J Zool. 1988;214:21-44.

15. Mukai Y, Tuzan AD, Lim LS, Raehanah MSS, Wahid N, Senoo S. Development of sensory organs in larvae of African catfish, Clarias gariepinus. J Fish Biol. 2008;73:1648-61.

16. Pouomogne V. Capture-based aquaculture of Clarias catfish: case study of the Santchou fishers in western Cameroon. In: A. Lovatelli, P.F. Holthus editors. Capture based aquaculture. Global overview. FAO, Rome. FAO Fisheries Technical Paper No 2008, 508:3-108.

17. Bruton MN. The food and feeding behavior of Clarias gariepinus in Lake Sibaya, South Africa, with emphasis on its role as a predator of cichlids. Trans Zoo Soci Lond. 1979;35:47-114. 
18. Huskey SH, Turingan RG. Variation in preyresource utilization and oral jaw gape between two populations of largemouth bass, Micropterus salmoides. Environ Biol Fishes. 2001;61:185-94.

19. Wainwright $P C$, Richard BA. Predicting patterns of prey use from morphology of fishes. Environ Biol Fishes. 1995;44:97-113.

20. Skelton P. A complete guide to the freshwater fishes of Southern Africa. Cape Town: Struik Publishers; 2001.
21. Van der Waal BCW. Survival strategies of sharptooth catfish Clarias gariepinus in desiccating pans in the northern Kruger National Park. KoedoeAfrican Protected Area Conserv Sci. 1998;41:131-8.

22. Ellender BR, Weyl OL. A review of current knowledge, risk and ecological impacts associated with non-native freshwater fish introductions in South Africa. Aquat Invasions. 2014;9:117-32.

\section{Submit your next manuscript to BioMed Central and we will help you at every step:}

- We accept pre-submission inquiries

- Our selector tool helps you to find the most relevant journal

- We provide round the clock customer support

- Convenient online submission

- Thorough peer review

- Inclusion in PubMed and all major indexing services

- Maximum visibility for your research

Submit your manuscript at

www.biomedcentral.com/submit 